\title{
Comparative evaluation of the effect of cold ceramic and MTA-Angelus on cell viability, attachment and differentiation of dental pulp stem cells and periodontal ligament fibroblasts: an in vitro study
}

Sedigheh Khedmat ${ }^{1}$, Pegah Sarraf ${ }^{1}$, Ehsan Seyedjafari ${ }^{2}$, Parisa Sanaei-rad ${ }^{3}$ and Faranak Noori ${ }^{1 *}$

\begin{abstract}
Background: Biocompatibility and induction of mineralized tissue formation are the properties expected from a material used in vital pulp therapy and repair of perforations. Cold ceramic (SJM, Iran; CC) is a newly introduced calcium silicate-based cement for above mentioned therapeutic applications. This in-vitro study aimed to compare the effect of CC and White MTA-Angelus (MTA) on cell viability, attachment, odontogenic differentiation, and calcification potential of human dental pulp stem cells (DPSCs) and periodontal ligament fibroblasts (PDLFs).

Methods: Cell viability of DPSCs and PDLFs was assessed using MTT on days 1, 3, 7, and $14(n=9)$ in contact with freshly mixed and set states of CC and MTA. Field emission scanning electron micrographs (FESEM) were taken to evaluate cell-bioceramic interaction $(n=6)$. Gene expression levels of osteo/odontogenic markers (Dentin sialophosphoprotein, Dentin matrix protein 1, Collagen type I alpha 1, and Alkaline phosphatase (DSPP, DMP1, COL 1A1, and $A L P$, respectively) $(n=8)$ were assessed using grt-PCR. ALP enzymatic activity was evaluated to assess the mineralization potential. A two-way ANOVA test was applied, and $p<0.05$ was considered to be statistically significant.

Results: The effect of freshly mixed and set MTA and CC on the survival of DPSCs and PDLFs in all study groups was statistically similar and comparable to the positive control group ( $p>0.05)$; the only exception was for the viability of PDLFs in contact with freshly mixed cements on day 1 , showing a more significant cytotoxic effect compared to the control and the set state of materials $(p<0.05)$. PDLFs attached well on CC and MTA. The spread and pseudopodium formation of the cells increased on both samples from day 1 to day 14. Contact of MTA and CC with DPSCs similarly increased expression of all dentinogenesis markers studied on days 7 and 14 compared to the control group ( $p<0.001$ ), except for DSPP expression on day 7 ( $p=0.46$ and $p=0.99$ for MTA and CC, respectively).
\end{abstract}

Conclusions: Within the limitation of this in-vitro study, cold ceramic and MTA-Angelus showed high biocompatibility and induced increased expression of osteo/dentinogenic markers. Therefore, cold ceramic can be a suitable material for vital pulp therapy and the repair of root perforations.

Keywords: Calcium silicate, Cell survival, Cell differentiation, Gene expression, MTA-Angelus, Dental pulp

\footnotetext{
${ }^{*}$ Correspondence: f.noori1371@gmail.com

${ }^{1}$ School of Dentistry, Tehran University of Medical Sciences, Tehran, Iran

Full list of author information is available at the end of the article

Sedigheh Khedmat and Pegah Sarraf are co-first authors.
}

(C) The Author(s) 2021. Open Access This article is licensed under a Creative Commons Attribution 4.0 International License, which permits use, sharing, adaptation, distribution and reproduction in any medium or format, as long as you give appropriate credit to the original author(s) and the source, provide a link to the Creative Commons licence, and indicate if changes were made. The images or other third party material in this article are included in the article's Creative Commons licence, unless indicated otherwise in a credit line to the material. If material is not included in the article's Creative Commons licence and your intended use is not permitted by statutory regulation or exceeds the permitted use, you will need to obtain permission directly from the copyright holder. To view a copy of this licence, visit http://creativecommons.org/licenses/by/4.0/. The Creative Commons Public Domain Dedication waiver (http://creativeco mmons.org/publicdomain/zero/1.0/) applies to the data made available in this article, unless otherwise stated in a credit line to the data. 


\section{Background}

Various materials are used in endodontic treatments to repair root perforations, apexification, and vital pulp therapy. Proper sealability, biocompatibility, and inducing hard tissue regeneration are among the expected properties of a material used in these treatments [1]. Promoting cell attachment and odontogenic differentiation are desirable properties of such materials. These properties not only reflect the biocompatibility of the material but also show that the material may serve as a scaffold for the adjacent cells leading to the construction of mineralized tissues [2]. Calcium silicate-based cements (CSCs) were introduced for the mentioned therapeutic applications. ProRoot MTA (ProRoot MTA, Dentsply, Tulsa, OK) was the earliest member of CSCs [3]. Other commercial bioceramic cements were introduced after introducing this applicable material, such as MTA-Angelus (Angelus, Londrina, Brazil). Despite many advantages, these materials have some drawbacks, such as difficult handling and long setting time [4]. In spite of the manufacturer's claim (15 min), the setting time of MTA Angelus can take approximately $3 \mathrm{~h}$ [5]. Moreover, the acidic environment and blood contamination can prolong the setting time even for a week [6]. Cold Ceramic (SJM co, Yazd, Iran; CC) is a newly introduced bioceramic with similar applications of other CSCs, to overcome the shortcomings of previous materials. The radiopacifier of this cement is barium sulfate, which has shown non-toxic properties [7]. According to the manufacturer, the initial and final setting times are $15 \mathrm{~min}$ and $24 \mathrm{~h}$, respectively [8]. In a study comparing the effect of blood and saliva contamination on $\mathrm{CC}$ and ProRoot MTA, the results showed that the sealing ability of CC is better than MTA in blood-contaminated condition and at least similar to MTA in other conditions [9]. In an animal model, the tissue reaction to $\mathrm{CC}$ was comparable to ProRoot MTA, indicating that both materials were biocompatible [10]. Also, an electron scanning microscope (SEM) evaluation revealed that the CC and ProRoot MTA were similar in terms of marginal adaptation [8]. However, the effect of this cement on human cells has not been studied before. The aim of this in-vitro study was to compare the effect of CC and White MTA Angelus (MTA) on cell viability, attachment, odontogenic differentiation, and calcification potential of human dental pulp stem cells (DPSCs) and periodontal ligament fibroblasts (PDLFs).

\section{Methods}

\section{Preparation of MTA and CC samples}

MTA (MTA-Angelus white, Angelus, Londrina, Brazil) and CC (SJM co, Yazd, Iran) were prepared according to the manufacturers' instructions [The components of the cements are provided in Additional file 1]. The samples were cast under the aseptic condition in $10 \mathrm{~mm}$ diameter and $1.5 \mathrm{~mm}$ height plexiglass mold (Pars, Karaj, Iran). All the samples were exposed to UV light for $20 \mathrm{~min}$ on each side. The samples targeted to be evaluated in the set state were incubated for $72 \mathrm{~h}$ (to ensure complete setting) at $37{ }^{\circ} \mathrm{C}$ and $95 \%$ relative humidity. The samples were divided according to the tested materials and target cells. The study design is shown in Fig. 1.

\section{Cell culture}

This study was performed on human dental pulp stem cells (IBRC: C11306) and human periodontal ligament fibroblasts (IBRC: C11326) obtained from the Iranian Biological Resource Center. The cells were cultured in Dulbecco's minimum essential medium (DMEM; Gibco) containing 10\% fetal bovine serum (FBS; Sigma) and $100 \mathrm{U} / \mathrm{ml}$ penicillin, $100 \mu \mathrm{g} / \mathrm{ml}$ streptomycin (Sigma) and incubated at $37^{\circ} \mathrm{C}$ in $5 \% \mathrm{CO}_{2}$.

\section{Cell viability}

The effect of materials on cell viability of DPSCs and PDLFs was assessed using MTT assay (3-(4, 5-dimethylthiazol-2-yl)-2,5-diphenyltetrazolium bromide). The

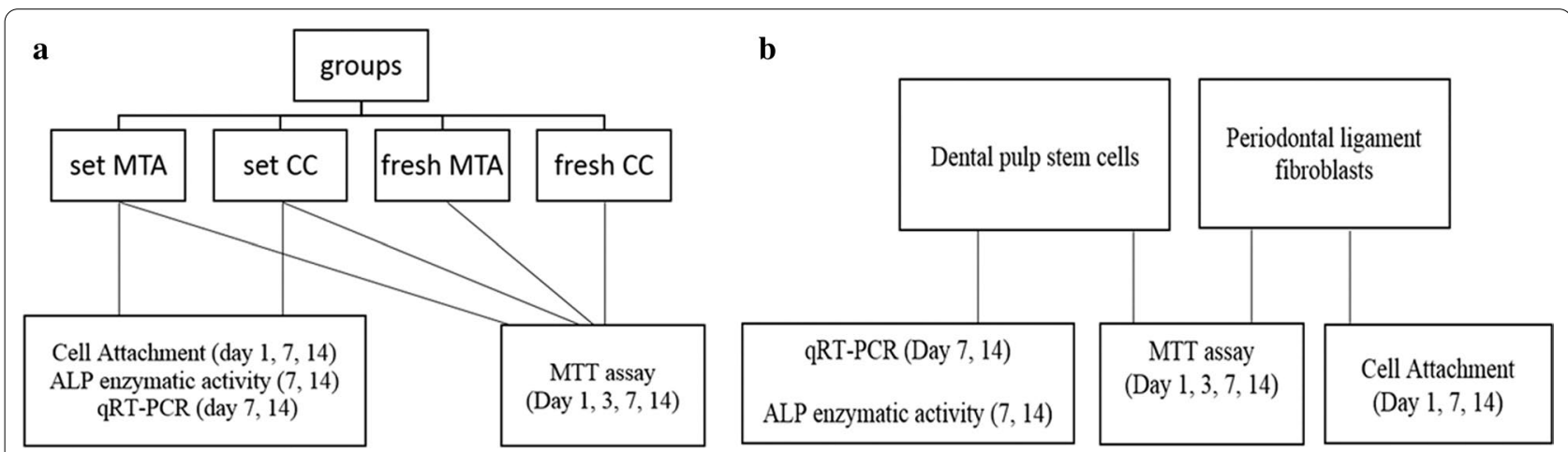

Fig. 1 The study design. a Experimental groups. b Cells used in each assessment 
samples were investigated in two states: 1 - freshly mixed 2 - set. The cytotoxicity assays were conducted in triplicate in order to validate the observed results. In each of these replications, 3 samples of each study group (including MTA-Angelus, Cold Ceramic, and the controls) were prepared and examined. Therefore, a total of 288 samples were examined ( $\mathrm{n}=9$ per group). Both freshly mixed and set groups were transferred to 24-well culture plates containing DMEM for extraction. The area to volume ratio of samples for extraction was according to ISO 10993-5 [11]. Then, the extracts were passed through a $0.22 \mu \mathrm{m}$ filter. Finally, the extracts were mixed with $10 \%$ FBS and $100 \mathrm{IU} / \mathrm{ml}$ of penicillin-streptomycin. An equivalent of $100 \mu \mathrm{l}$ from different extract groups was added to 24-well plates containing DPSCs or PDLFs and culture medium (each plate contained $3.5 \times 10^{4}$ cells $/ \mathrm{cm}^{2}$ ). Culture medium without the addition of any extract and distilled water were used as the positive and negative controls, respectively. After 1, 3, 7, and 14 days of incubation, $50 \mu \mathrm{l}$ of MTT solution was added to the culture medium, and the plates were placed in a wrapped foil in the incubator for 3-4 $\mathrm{h}$. Then the culture medium containing MTT was removed, and $200 \mu \mathrm{l}$ of Dimethyl sulfoxide (DMSO) was added. Then $100 \mu \mathrm{l}$ of the above solution was inserted into a 96-well plate. Samples were read at $570 \mathrm{~nm}$ wavelength by ELISA reader (Stat Fax 2100, Awareness Technology Inc., Palm City, FL). Cell viability was calculated by dividing the mean absorption of each group by the mean absorption of the positive control group multiplied by 100 .

\section{Cell attachment}

This test was performed on PDLFs and the samples in the set state $(n=6)$. Self-curable glass ionomer (GC Fuji IX, GC Corporation, Tokyo, Japan) was prepared as the control group. $3.5 \times 10^{4}$ cells $/ \mathrm{cm}^{2}$ were seeded on discs, and DMEM culture medium was added with $10 \%$ FBS and $100 \mathrm{IU} / \mathrm{ml}$ penicillin-streptomycin. To investigate immediate and long-term cell/surface interactions, field emission scanning electron micrographs (FESEM, Sigma VP, Zeiss, Germany) were taken of the samples on days 1, 7, and 14. The preparation of the samples for FESEM assessment was as follows. The culture mediums of each well were removed, and the samples were washed twice in PBS. Then the cells were fixed with $2.5 \%$ glutaraldehyde solution. After $40 \mathrm{~min}$, the samples were rewashed with PBS. The samples were dried in ethanol solution at increasing concentrations $(30 \%, 50 \%, 70 \%, 90 \%$, and $100 \%$ ) for $10 \mathrm{~min}$ at each concentration and then airdried. Conducting process was then performed using the physical vapor deposition (PVD) technique (Coxen, CX-200, South Korea).

\section{Alkaline phosphatase activity (ALP)}

ALP activity of DPSCs was assessed on days 7 and 14 . DPSCs $\left(3.5 \times 10^{4}\right.$ cells $\left./ \mathrm{cm}^{2}\right)$ were seeded on the set samples of CC and MTA and incubated at $37{ }^{\circ} \mathrm{C}$ and $95 \%$ relative humidity. After 7 and 14 days of incubation, the surface culture medium was removed, then rinsed with $3 \mathrm{ml}$ PBS. Using $200 \mu \mathrm{L}$ of RIPA buffer, the enzyme was extracted from stem cells. To eliminate cell debris, the lysate was centrifuged at $15,000 \mathrm{rpm}$ at $4{ }^{\circ} \mathrm{C}$ for $20 \mathrm{~min}$. Then, the supernatant was collected, and ALP activity was evaluated with an ALP assay kit (Pars Azmun, Tehran, Iran).

\section{Osteo/odontogenic differentiation}

DPSCs $\left(3.5 \times 10^{4}\right.$ cells $\left./ \mathrm{cm}^{2}\right)$ were seeded on the discs of set samples, DMEM was added, and kept in an incubator at $37{ }^{\circ} \mathrm{C}$ and $5 \% \mathrm{CO}_{2}$ for $3 \mathrm{~h}$ to establish cell attachment $(n=8)$. Then the basal medium of each well was replaced with $100 \mathrm{nM}$ dexamethasone, $0.2 \mathrm{mM}$ ascorbic acid 2-phosphate, and $10 \mathrm{mM} \beta$-glycerophosphate (Sigma-Aldrich) as differentiation medium. To evaluate the osteo/odontogenic differentiation of DPSCs, the relative expression of specific osteo/dentinogenesis markers, including DMP1, DSPP, COL 1A1, and ALP was measured on days 7 and 14 by the quantitative RT-PCR method. The primer sequences of the examined markers are listed in Table 1. mRNAs were extracted from the cells of study groups using a Hybrid$\mathrm{R}^{\mathrm{TM}}$ kit (Gene All, Korea) according to the manufacturer's manual. cDNA synthesis was performed using $1 \mu \mathrm{g}$ RNA, $0.5 \mu \mathrm{L}$ dNTPs mix $(10 \mathrm{mM}), 1 \mu \mathrm{L}$ of random hexamer primer $(10$ p.m.), $2 \mu \mathrm{L}$ reveres transcription buffer, and $0.3 \mu \mathrm{L}$ RT enzyme $(200 \mathrm{U} / \mu \mathrm{L})$ (Yekta-Tajhis, Iran). Reverse transcription was performed at $25^{\circ} \mathrm{C}$ for $10 \mathrm{~min}$ and $42{ }^{\circ} \mathrm{C}$ for $60 \mathrm{~min}$.

Quantitative real-time PCR reactions were prepared in a final volume of $20 \mu \mathrm{L}$ containing $1 \mu \mathrm{L}$ of each primer (forward and reverse, 10 p.m.), $1 \mu \mathrm{L}$ cDNA, and $10 \mu \mathrm{L}$ SYBR $^{\circledR}$ Premix Ex Taq ${ }^{\text {TM }}$ II (Perfect Real Time; Takara, Dalian, China). StepOne ${ }^{\mathrm{TM}}$ Software v2.2.2 analyzed threshold cycles (Cq). The relative expression of target genes was determined using the $\Delta \Delta C T$ method and REST $^{\circledR} 2009$.

\section{Statistical analysis}

Statistical analyses were performed using GraphPad Prism software, Version 6 (GraphPad Software, San Diego CA, USA). Mean \pm standard deviation (SD) was calculated [Additional file 2], and a two-way ANOVA test was applied for analyzing the differences. P-values less than 0.05 were considered to be statistically significant. 
Table 1 Primer sequences (Seq. (5-3) of the target differentiation markers

\begin{tabular}{|c|c|c|c|c|c|}
\hline Number & Name & Seq. $(5-3)$ & TM & $\begin{array}{l}\text { Per } 13-20 \mu \mathrm{l} \text { (total } \\
\text { volume) }(\mu \mathrm{l})\end{array}$ & $\begin{array}{l}\text { Concentration } \\
\text { (p/mol) }\end{array}$ \\
\hline \multirow[t]{2}{*}{1} & H-beta Actin-F & CTT CCTTCCTGG GCAT & 60 & 1 & 10 \\
\hline & H-beta Actin-R & GTC TTT GCG GAT GTC CA & & & \\
\hline \multirow[t]{2}{*}{2} & DSPP-F & CCA TTC CAG TTC CTC AAA G & 60 & 1 & 10 \\
\hline & DSPP-R & TGG CAT TTA ACT CAT CCT GTA & & & \\
\hline \multirow[t]{2}{*}{3} & ALP-F & GCA CCT GCC TTA CTA ACT & 60 & 1 & 10 \\
\hline & $A L P-R$ & AGA CAC CCA TCC CAT CT & & & \\
\hline \multirow[t]{2}{*}{4} & DMP F & TTCTTTGTGAACTACGGAG & 60 & 1 & 10 \\
\hline & DMPR & TTGATACCTGGTTACTGGG & & & \\
\hline \multirow[t]{2}{*}{5} & $\mathrm{H}$-collagen1a1-F & GCC AAG GGT CTG ACT G & 60 & 1 & 10 \\
\hline & $\mathrm{H}$-collagen1a1-R & CCC ATC ACA CCA GCC T & & & \\
\hline
\end{tabular}

Beta Actin was used as the housekeeping-gene. F, Forward; R, Reverse; concentration used $=10 \mathrm{p} / \mathrm{mol}$, volume $=1 \mu \mathrm{ll}$, melting temperature (Temperature melting $(\mathrm{TM})=60^{\circ} \mathrm{C}$

\section{Results}

\section{Cell viability}

The results of the MTT assays are shown in Fig. 2. The effects of freshly mixed and set MTA and CC on the viability of DPSCs and PDLFs in all time points were statistically similar and comparable to the positive control group $(p>0.05)$. The only exception was the effect of freshly mixed CC and MTA on PDLFs on day 1, which showed a significant cytotoxic effect compared to the positive control group $(p<0.01)$ and the set state of the samples $(p=0.0198$ and $p=0.0046$ for MTA and $\mathrm{CC}$, respectively). Distilled water (negative control) showed a more cytotoxic effect in comparison to the other groups in all of the studied time points $(p<0.001)$. $\mathbf{a}$
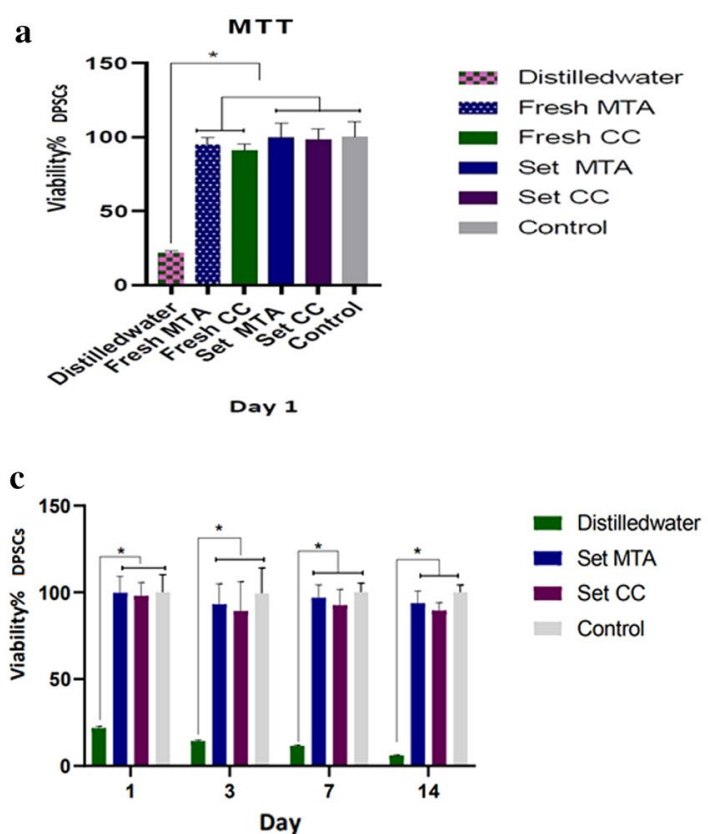

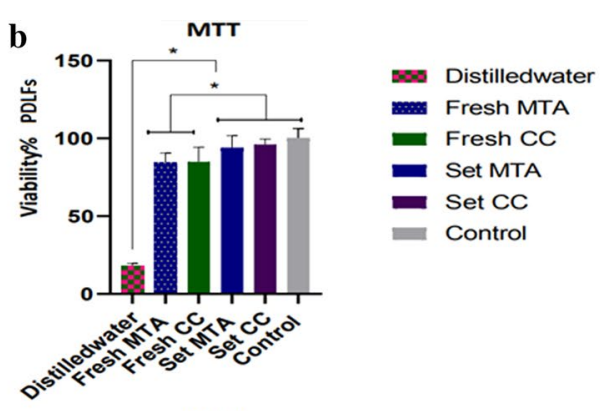

Day 1

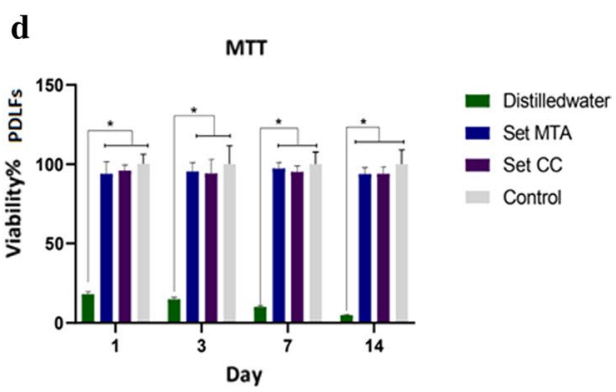

Fig. 2 The results of the MTT assays. a comparison of DPSCs viability after exposure to freshly mixed and set materials on day 1. $\mathbf{b}$ comparison of PDLFs viability after exposure to freshly mixed and set materials on day 1 , indicating a more significant cytotoxic effect of freshly mixed of both materials compared to the control group and the set state of substances $(p<0.05)$. $\mathbf{c}$ and $\mathbf{d}$ DPSCs and PDLFs viability after exposure to set state of materials for 1, 3, 7, and 14 days showed no significant difference among the study groups and the positive control $(p>0.05)$. ${ }^{*}$ Indicates statistically significant difference 


\section{Cell attachment}

As shown in Fig. 3, PDLFs attached favorably on both CC and MTA samples. The spread and pseudopodium formation of the cells increased on both samples over time from day 1 to day 14. Cell attachment was observed on GI samples. However, demonstration of round-shaped cells and poorly branched processes indicated poor cell attachment.

\section{ALP activity}

The results of the ALP activity are shown in Fig. 4. The enzymatic activity of DPSCs was significantly higher when they were in contact with CC and MTA compared to the control in all time intervals $(p<0.001)$. Cells in contact with MTA groups showed higher ALP activity in all time points compared to $\mathrm{CC}$, but this difference was not statistically significant $(p=0.26)$.

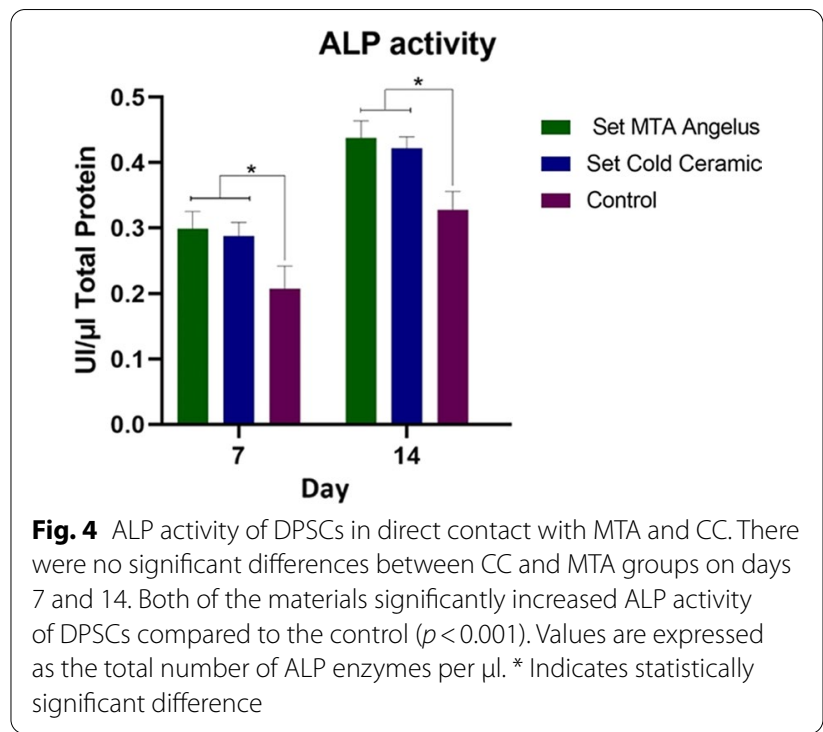

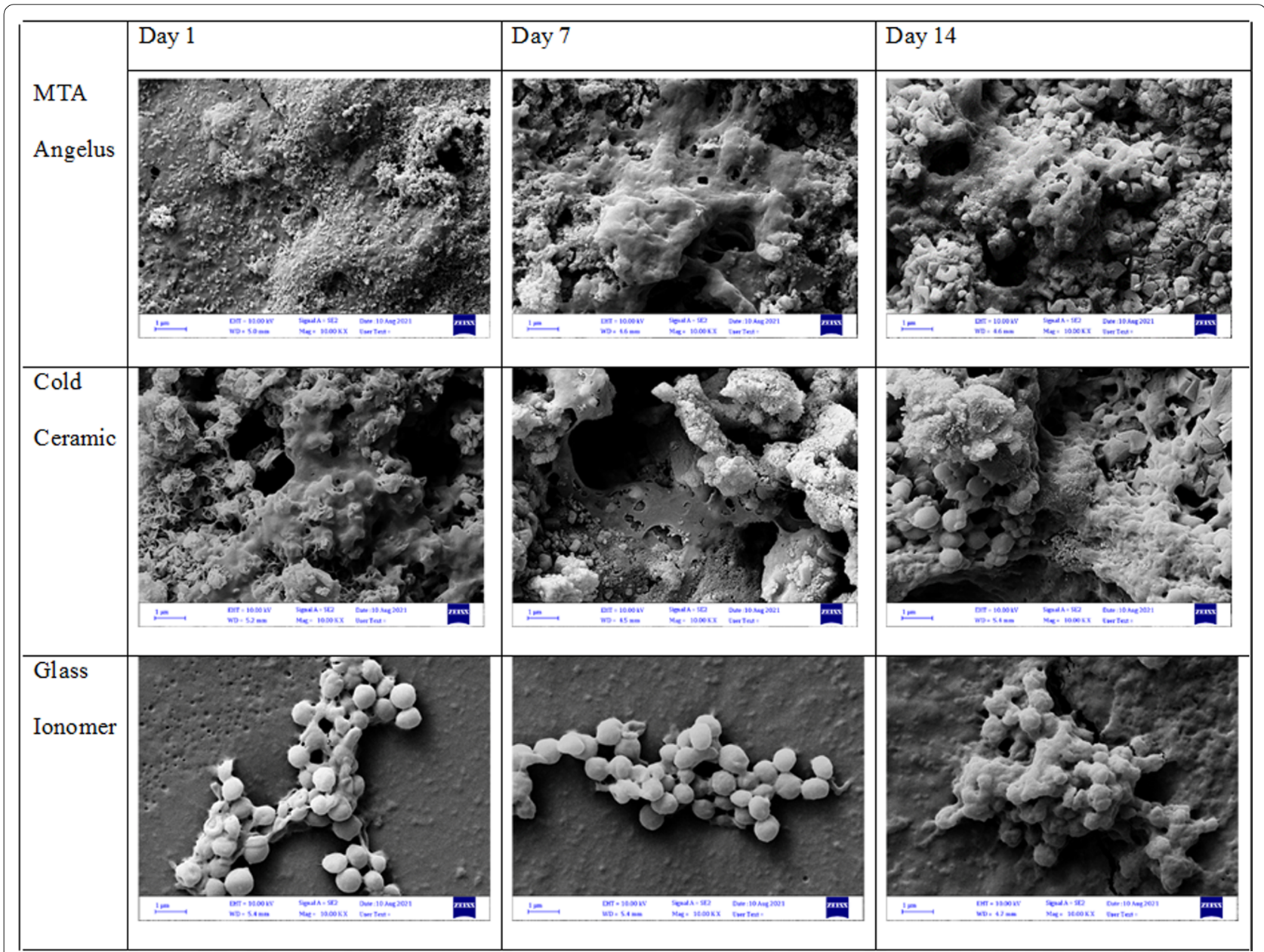

Fig. 3 A field emission scanning electron micrograph (FESEM) of PDLFs seeded on MTA, CC, and Gl (magnification 10,000 ×). Cells attached well and similarly on MTA and CC; however, cell attachment on Gl samples was poor 


\section{q RT-PCR}

The results of the relative expression of target odontogenic markers are shown in Fig. 5. MTA and CC contact with DPSCs resulted in an increased expression of dentinogenesis markers including DSPP, DMP1, COL 1A1, and ALP compared to the control group on days 7 and $14(p<0.001)$. The only exception was DSPP gene expression on day 7 of contact with MTA and CC samples, which was similar to the control $(p=0.46$ and $p=0.99$, respectively). However, these values were significantly higher than the control on day $14(p<0.001)$. There was no significant difference between CC and MTA samples regarding time periods and markers expression $(p>0.05)$.

\section{Discussion}

This in-vitro study aimed to evaluate and compare certain biological effects of CC and MTA on DPSCs and PDLFs. Overall, both cements showed high biocompatibility and favorable cell attachment, and also induced increased expression of osteo/odontogenic differentiation markers.

To evaluate the biocompatibility of a material in direct contact with vital tissues, various tests such as the assessment of cytotoxicity are compulsory [12]. Various methods and cell lines were used in previous studies to examine the biocompatibility of CSCs [13-15]. Also, some studies have been examined different concentrations of the studied materials (i.e., serial dilution method) $[2,16]$. Despite providing comprehensive information about the studied subjects and compliance with laboratory standards, these concentrations may differ from those used in biological conditions and clinical applications. Therefore, it is necessary to interpret the results of these studies with caution. Also, due to these variations in methods, target cells, and concentrations of tested materials, it is impossible to compare the results of different studies reliably. In the present study, the ISO-10993-5 standard was used to evaluate the cytotoxic effect of the studied materials. This standard describes the necessary tests, protocols, and standard concentrations to evaluate the biological effects of medical substances in contact with body tissues in a laboratory setting [11]. Due to the standardization, it is easier to compare the results of this study with similar studies accurately and interpret the result for clinical situations.

DPSCs and PDLFs are in direct contact with the applied sealing material in vital pulp therapy and repair of perforations. Therefore, to simulate clinical conditions, these cells were selected for the present study.

MTT has been shown as a reliable method for in-vitro cytotoxicity evaluation of materials used in endodontics [17]. Previous studies indicated that MTA Angelus has high biocompatibility $[16,18,19]$. While the results of one study showed that cell proliferation increases in the
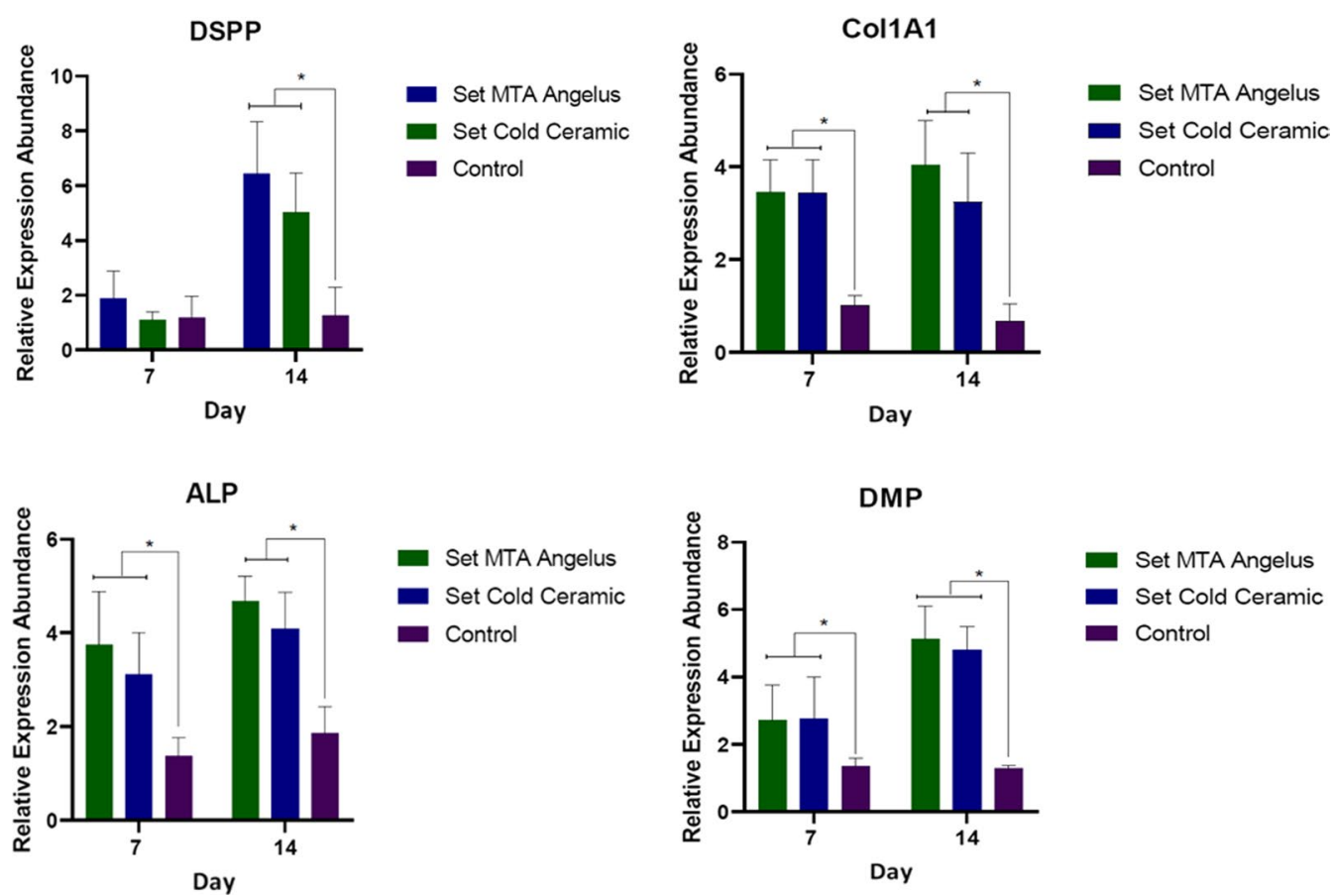

Fig. 5 Relative expression of target odontogenic markers. MTA and CC increased the expression of odontogenic markers by DPSCs, except in DSPP expression on the 7-day time interval. ${ }^{*}$ Indicates statistically significant difference 
presence of MTA Angelus [16], another study have indicated that its effect is similar to that of the control group (plain culture medium) [20]. The difference in the results of these studies could be due to the use of different cell lines (DPSCs or fibroblasts), the extraction protocol, and the concentrations of the extract. As mentioned earlier, the use of ISO-10993 makes it possible to interpret and compare the results of in-vitro studies more accurately.

In the clinical application, CSCs are placed on living tissue immediately after mixing. Therefore, in-vitro assessment of the cements in the freshly mixed state seems necessary to predict the initial response of the tissues. Furthermore, evaluation of the set state of the cements may indicate the long-term response of cells and tissues to the materials [21].Therefore, in this study, the possible cytotoxicity of the eluates from both freshly mixed and set states of the cements were evaluated..

The results of the present study showed that the biocompatibility of CC in freshly mixed and set states at all time points studied was statistically similar to MTA Angelus. The cell viability in all groups was similar to the positive control group. The only exception was the effect of freshly mixed materials on PDL fibroblasts, which was lower than the control, which could be attributed to the alkaline $\mathrm{pH}$ of the freshly mixed cements [22]. The difference in cell reaction may be related to the growth rate of the cells $[23,24]$. The high growth rate of DPSCs may have compensated for the toxicity of the samples, but this compensation did not occur in fibroblasts due to the slower growth rate compared to DPSCs.

According to ISO-10993-5, substances that reduce cell viability by more than $30 \%$ are considered cytotoxic [25]. None of the study groups showed a mean survival rate of less than $89 \%$ in the present study. Therefore, it can be concluded that CC and MTA are biocompatible in both fresh and set states.

Another method to assess the biocompatibility of a material is to evaluate the ability of a selected cell line to attach to the material's surface (16). Various factors affect cell-substance interaction, including the surface porosity and roughness of the material [26]. The surface roughness promotes cell attachment and proliferation [27]. The results of the present study showed that PDLFs could properly attach on the surfaces of both CC and MTA cements. Cell spreading, intercellular communication, and pseudopodia formation were observed on both studied cements over time. This finding was similar to the previous studies on different cell-bioceramic interactions $[28,29]$.

Alkaline phosphatase (ALP) plays an essential role in the initial formation of mineralized tissues and induction of hydroxyapatite deposition in collagenous matrices. This enzyme stimulates dentin matrix formation by pulp tissue; hence, it is essential for healing and repairing after pulpal injury [30]. The results of the present study showed that CC and MTA both could increase ALP enzymatic activity. This finding was in accordance with previous studies $[28,31]$. Therefore, it may be assumed that the contact of CC and MTA with DPSCs leads to increased mineralization activity of these cells. This finding is important because it demonstrates the potential of these materials to induce dentin bridge formation in vital pulp therapy.

CSCs induce mesenchymal stem cells differentiation by creating an osteo/odontogenic inductive medium [32, 33]. The hydrolysis of the cements and production of calcium hydroxide might be the reason for this bioactive property [22]. The result of this cell differentiation is an increase in the expression of specific mineralization genes. DSPP, DMP1, COL 1A1, and ALP are among the most significant dentinogenesis markers [28]. In this study, the mentioned genetic markers were used to evaluate the odontogenic differentiation of DPSCs. In 2015 a review study by Rathinam et al. [34] found that various bioceramics including Biodentine, MTA Angelus, OrthoMTA, MicroMega MTA, Portland cement, Endocem, and ProRoot MTA increased osteo/ odontogenic markers expression similarly. On the other hand, other cements such as iRoot BP Plus, Bioaggregate, and CEM increased the expression of those markers more than ProRoot MTA. The reasons for the difference between different tricalcium silicate-based cements have not been identified so far [34]. However, differences in setting time, initial and final $\mathrm{pH}$ of the cements, the rate of calcium ion release [21,35], as well as the type of culture medium used in the control group (conventional nutrient culture medium versus differentiation medium) may be the justification for the differences in relative expression. The results of the present study showed that both MTA and CC increased the expression of DSPP, DMP1, COL 1A1, and ALP markers similarly, which was higher compared to the control group. However, this increase was not observed for DSPP expression on day 7. Though, with the increase of exposure time to 14 days, the expression of this marker increased in both CC and MTA and was higher than the control group. These results indicate that the application of MTA and CC in vital pulp therapy not only provides a proper seal for the exposed pulp tissues [9, 36] but also stimulates odontogenic differentiation of the DPSCs resulting in dentinal bridge formation.

The present study investigated certain biological effects of two types of CSCs on the target cells in vital pulp therapy and root perforation repair, in a laboratory setting. However, in-vivo studies are recommended to 
better investigate and generalize the effects of these biomaterials in the clinical practice.

\section{Conclusions}

Within the limitation of this in-vitro study, cold ceramic and MTA-Angelus have high biocompatibility. These materials increase the expression of osteo/odontogenic differentiation markers. Also, Cell attachment occurs favorably on both of these materials. Therefore, cold ceramic can be a suitable material for vital pulp therapy and repair of root perforations.

\section{Abbreviations}

DPSCs: Dental pulp stem cells; PDLFs: Periodontal ligament fibroblasts; MTA: MTA-Angelus; CC: Cold ceramic; DMP1: Dentin matrix protein 1; DSPP: Dentin sialophosphoprotein; COL 1A1: Collagen, type I, alpha 1; ALP: Alkaline phosphatase.

\section{Supplementary Information}

The online version contains supplementary material available at https://doi. org/10.1186/s12903-021-01979-1.

Additional file 1. The chemical components of MTA Angelus and Cold Ceramic cements.

Additional file 2 . The datasets generated and analyzed during the current study.

\section{Acknowledgements}

This study was financially supported by Tehran University of Medical Sciences (grant No: 99-3-113-50118).

\begin{abstract}
Authors' contributions
SK: Concept and design, critical and scientific revision of the manuscript, data analysis/interpretation. PS: Concept and design, critical and scientific revision of the manuscript, data analysis/interpretation. ES: Consulting, design, and supervision of laboratory tests. PSR: Concept and design, critical and scientific revision of the manuscript, data analysis/interpretation. FN: Concept and design of the study, review of the literature, data analysis/interpretation, drafting the manuscript. All authors read and approved the final manuscript.
\end{abstract}

\section{Funding}

This study was financially supported by Tehran University of Medical Sciences (grant No: 99-3-113-50118).

\section{Availability of data and materials}

All data generated or analyzed during this study are included in this article as "Additional file 2" in the Statistical analysis part of the method section.

\section{Declarations}

\section{Ethics approval and consent to participate}

This manuscript was approved by the Ethical Committee of Research in Tehran University of Medical Sciences (TUMS), School of Dentistry (ID: IR.TUMS. DENTISTRY.REC.1399.139.

\section{Consent for publication \\ Not applicable.}

\section{Competing interests}

The authors declare that they have no competing interests.

\section{Author details}

${ }^{1}$ School of Dentistry, Tehran University of Medical Sciences, Tehran, Iran. ${ }^{2}$ University of Tehran, Tehran, Iran. ${ }^{3}$ School of Dentistry, Arak University of Medical Sciences, Arak, Iran.

Received: 12 September 2021 Accepted: 16 November 2021

Published online: 07 December 2021

\section{References}

1. Ber BS, Hatton JF, Stewart GP. Chemical modification of proroot mta to improve handling characteristics and decrease setting time. J Endod. 2007;33(10):1231-4

2. Ahmed HMA, Luddin N, Kannan TP, Mokhtar Kl, Ahmad A. Cell attachment properties of portland cement-based endodontic materials: biological and methodological considerations. J Endod. 2014;40(10):1517-23.

3. Torabinejad M, Chivian N. Clinical applications of mineral trioxide aggregate. J Endod. 1999;25(3):197-205.

4. Huang TH, Shie MY, Kao CT, Ding SJ. The effect of setting accelerator on properties of mineral trioxide aggregate. J Endod. 2008;34(5):590-3.

5. Ha WN, Nicholson T, Kahler B, Walsh $\sqcup$. Mineral trioxide aggregatea review of properties and testing methodologies. Materials. 2017;10(11):1261.

6. Parirokh M, Farzaneh S, Hallajmofrad AR. Conservative management of unset mineral trioxide aggregate root-end filling: a case report. Iran Endod J. 2016;11(3):241-5.

7. Bortoluzzi EA, da Silveira Teixeira C, Broon NJ, Consolaro A, Pinheiro TN, da Fonseca Roberti Garcia L, et al. Tissue response to white mineral aggregate-based cement containing barium sulfate as alternative radiopacifier: a randomized controlled animal study. Microsc Res Tech. 2021;84(4):705-11.

8. Modaresi J, Hemati HR. The cold ceramic material. Dent Res J. 2018;15(2):85-8.

9. Hasheminia SM, Nejad SL, Dianat O, Modaresi J, Mahjour F. Comparing the sealing properties of mineral trioxide aggregate and an experimental ceramic based root end filling material in different environments. Indian J Dent Res. 2013;24(4):474-7.

10. Modaresi J, Yavari SAS, Dianat SO, Shahrabi S. A comparison of tissue reaction to MTA and an experimental root-end restorative material in rats. Aust Endod J. 2005;31(2):69-72.

11. Wallin RF, Arscott E. A practical guide to ISO 10993-5: cytotoxicity. Med Device Diagnos Ind. 1998;20:96-8.

12. Standardization IOf. ISO10993. Biological evaluation of medical devices. Geneva. 2009.

13. Petrović V, Opačić-Galić V, Živković S, Nikolić B, Danilović V, Miletić V, et al. Biocompatibility of new nanostructural materials based on active silicate systems and hydroxyapatite: in vitro and in vivo study. Int Endod J. 2015;48(10):966-75.

14. AlAnezi AZ, Jiang J, Safavi KE, Spangberg LS, Zhu Q. Cytotoxicity evaluation of endosequence root repair material. Oral Surg Oral Med Oral Pathol Oral Radiol Endod. 2010;109(3):e122-5.

15. Khedmat S, Dehghan S, Hadjati J, Masoumi F, Nekoofar MH, Dummer $\mathrm{PMH}$. In vitro cytotoxicity of four calcium silicate-based endodontic cements on human monocytes, a colorimetric MTT assay. Restor Dent Endod. 2014;39(3):149-54.

16. Tomás-Catalá C, Collado-González M, García-Bernal D, Oñate-Sánchez R, Forner L, Llena C, et al. Comparative analysis of the biological effects of the endodontic bioactive cements MTA-Angelus, MTA Repair HP and NeoMTA Plus on human dental pulp stem cells. Int Endod J. 2017;50:e63-72.

17. Pintor A, Queiroz L, Barcelos R, Primo L, Maia L, Alves G. MTT versus other cell viability assays to evaluate the biocompatibility of root canal filling materials: a systematic review. Int Endod J. 2020;53(10):1348-73.

18. Damas BA, Wheater MA, Bringas JS, Hoen MM. Cytotoxicity comparison of mineral trioxide aggregates and endosequence bioceramic root repair materials. J Endod. 2011;37(3):372-5.

19. de Oliveira NG, de Souza Araújo PR, da Silveira MT, Sobral APV, de Vasconcelos CM. Comparison of the biocompatibility of calcium silicate-based materials to mineral trioxide aggregate: systematic review. Eur J Dent. 2018;12(02):317-26. 
20. Koulaouzidou EA, Economides N, Beltes P, Geromichalos G, Papazisis K. In vitro evaluation of the cytotoxicity of ProRoot MTA and MTA Angelus. J Oral Sci. 2008;50(4):397-402.

21. Sanz JL, Guerrero-Gironés J, Pecci-Lloret MP, Pecci-Lloret MR, Melo M. Biological interactions between calcium silicate-based endodontic biomaterials and periodontal ligament stem cells: a systematic review of in vitro studies. Int Endod J. 2021;54:2025-43.

22. Maru V, Dixit U, Patil RSB, Parekh R. Cytotoxicity and bioactivity of mineral trioxide aggregate and bioactive endodontic type cements: a systematic review. Int J Clin Pediatr Dent. 2021;14(1):30-9.

23. Zhang H-Y, Liu R, Xing Y-J, Xu P, Li Y, Li C-J. Effects of hypoxia on the proliferation, mineralization and ultrastructure of human periodontal ligament fibroblasts in vitro. Exp Ther Med. 2013;6(6):1553-9.

24. Bae S, Kang B, Lee H, Luu H, Mullins E, Kingsley K. Characterization of dental pulp stem cell responses to functional biomaterials including mineralized trioxide aggregates. J Funct Biomater. 2021;12(1):15.

25. 10993-5. I. Biological evaluation of medical devices - part 5: test for in vitro cytotoxicity. International Organization for Standardization. 2009.

26. Anselme K, Bigerelle M. Modelling approach in cell/material interactions studies. Biomaterials. 2006:27(8):1187-99.

27. Zareidoost A, Yousefpour M, Ghaseme B, Amanzadeh A. The relationship of surface roughness and cell response of chemical surface modification of titanium. J Mater Sci Mater Med. 2012;23(6):1479-88.

28. Asgary S, Nazarian H, Khojasteh A, Shokouhinejad N. Gene expression and cytokine release during odontogenic differentiation of human dental pulp stem cells induced by 2 endodontic biomaterials. J Endod. 2014;40(3):387-92.

29. Sequeira DB, Seabra CM, Palma PJ, Cardoso AL, Peça J, Santos JM. Effects of a new bioceramic material on human apical papilla cells. J Funct Biomater. 2018;9(4):74.

30. Haniastuti T, Susilowati H, Rinastiti M. Viability and alkaline phosphatase activity of human dental pulp cells after exposure to yellowfin tuna bone-derived hydroxyapatite in vitro. Int J Dent. 2020;2020:8857534.

31. Bortoluzzi EA, Niu LN, Palani CD, El-Awady AR, Hammond BD, Pei DD, et al. Cytotoxicity and osteogenic potential of silicate calcium cements as potential protective materials for pulpal revascularization. Dent Mater. 2015;31(12):1510-22.

32. Seo M-S, Hwang K-G, Lee J, Kim H, Baek S-H. The effect of mineral trioxide aggregate on odontogenic differentiation in dental pulp stem cells. J Endod. 2013;39(2):242-8.

33. Okabe T, Sakamoto M, Takeuchi H, Matsushima K. Effects of pH on mineralization ability of human dental pulp cells. J Endod. 2006;32(3):198-201.

34. Rathinam E, Rajasekharan S, Chitturi RT, Martens L, De Coster P. Gene expression profiling and molecular signaling of dental pulp cells in response to tricalcium silicate cements: a systematic review. J Endod. 2015:41(11):1805-17.

35. Wongwatanasanti N, Jantarat J, Sritanaudomchai H, Hargreaves KM. Effect of bioceramic materials on proliferation and odontoblast differentiation of human stem cells from the apical papilla. J Endod. 2018;44(8):1270-5.

36. Parirokh M, Torabinejad M, Dummer P. Mineral trioxide aggregate and other bioactive endodontic cements: an updated overview-part I: vital pulp therapy. Int Endod J. 2018;51(2):177-205.

\section{Publisher's Note}

Springer Nature remains neutral with regard to jurisdictional claims in published maps and institutional affiliations.

Ready to submit your research? Choose BMC and benefit from:

- fast, convenient online submission

- thorough peer review by experienced researchers in your field

- rapid publication on acceptance

- support for research data, including large and complex data types

- gold Open Access which fosters wider collaboration and increased citations

- maximum visibility for your research: over $100 \mathrm{M}$ website views per year

At BMC, research is always in progress.

Learn more biomedcentral.com/submissions 